\title{
Management of post-intubation tracheal stenoses using the endoscopic approach
}

\author{
S. Cavaliere, M. Bezzi, C. Toninelli, P. Foccoli
}

ABSTRACT: Management of post-intubation tracheal stenoses using the endoscopic approach. S. Cavaliere, M. Bezzi, C. Toninelli, P. Foccoli.

Background and Aim. Tracheal stenosis is a common complication of intubation with or without subsequent tracheotomy whose management remains poorly defined. Over 600 post-intubation tracheal stenoses have been treated in our centre since 1982: the aim of this study was to determine the safety and efficacy of our endoscopic approach.

Methods. This retrospective study includes 113 new cases treated between 1998 and 2001 . We chose this period to have a standardised technique and a significant number of cases with a sufficiently long follow up (28-78 months). Forty patients who did not meet the criteria for "true stenosis" (granulomas, pseudoglottic stenosis, etc.) were excluded from the study.

Results. 73 patients $(50 \pm 21$ years) entered the study: $13(18 \%)$ web-like and $60(82 \%)$ complex stenoses. Most web-like stenoses were successfully treated with Laser Assisted Mechanical Dilation (LAMD) alone; among complex stenoses LAMD was sufficient to treat 13 patients (22\%), whereas 47 patients $(\mathbf{7 8 \%})$ required stent placement: 22 had their stent removed after one year and did not require any further therapy, 13 inoperable patients required permanent stent and 12 were referred to surgery after failure of multiple endoscopic treatments. No permanent complications secondary to endoscopic treatment were observed. 48 patients $(66 \%)$ obtained a stable, good result with the endoscopic procedure, $13(18 \%)$ required a permanent stent while 12 patients $(16 \%)$ were referred to surgery.

Conclusions. Our results indicate that the endoscopic treatment of post-intubation tracheal stenoses performed in an expert setting can be considered a safe first-line therapy, leaving some selected cases and the relapsing stenoses, for surgical resection.

Monaldi Arch Chest Dis 2007; 67: 2, 73-80.

Unit of Respiratory Endoscopy and Laser Therapy; Spedali Civili of Brescia, Italy.

Correspondence: Dr. Sergio Cavaliere, Centro di Endoscopia Respiratoria e Laserterapia, Spedali Civili di Brescia, P.zzale Spedali Civili 1, 25100 Brescia, Italy; e-mail: segreteria.scbendr@spedalicivili.brescia.it

\section{Introduction}

Prolonged intubation and potential subsequent tracheotomy may cause iatrogenic tracheal stenosis in some predisposed patients or when the safety criteria for intubation and tracheotomy are not followed (high volume-low pressure cuffs, performing tracheotomy without cartilaginous damages, preventing infections, etc.) [1-3].

The therapeutic approach to this complication has not been established and depends on the severity of airway narrowing. Anatomical features such as the presence or absence of tracheomalacia or involvement of the cartilaginous structures certainly influence selection of the therapeutic modality. According to many authors [4-8], surgical resection and reconstruction of post-intubation tracheal stenosis is the treatment of choice and interventional bronchoscopy is only considered as a bridge to surgical treatment, predominantly in emergency situations. However, in some cases, surgery is not recommended because of the extent of the stenosis (>50\% of the trachea or multi-focal involvement) or for all contraindications to an open surgery. Therefore several less invasive endoscopic techniques have been proposed for the treatment and palliation of symptoms related to tracheal stenosis. These therapeutic options include laser resection, bronchoscopic dilation and tracheal stenting. Multiple studies have reported variable success rates of these endoscopic treatments ranging from 32 [9] to 66 percent [10], regardless of the type of stenosis or endotracheal intervention [11-25].

However, most of these reports are based on a limited number of patients; many of these were treated over very extensive periods of time during which endoscopic techniques have evolved, making the evaluation of therapeutic approach impossible. Additionally, the follow-up period was short, particularly for the most recent cases.

Brichet's 1999 study on the multidisciplinary approach to the management of post-intubation 
tracheal stenoses [25] concludes that therapeutic bronchoscopy can offer initial conservative management applicable to almost all patients. The bronchoscopic approach allows patients to be prepared safely for possible curative surgery if the initial endoscopic treatment fails. In very selected cases such as web-like stenosis, Laser Assisted Mechanical Dilation (LAMD) alone can be curative with a $66 \%$ success rate after one or more sessions according to Mehta et al. [10], whereas the failure rate of surgery in every type of stenosis is about $5-15 \%[5-8,26,27]$.

In the past 20 years over five hundred patients have been treated at our referral centre for post-intubation tracheal stenosis; since our first endoscopic tracheal stent placement in 1987 [15], more than 250 post-intubation tracheal stenoses were stented requiring a total of 356 prostheses.

It took several years to formulate a uniform approach to tracheal stenoses, to gather a sufficient number of patients treated with this same standardised approach and to follow them for an extensive period of time.

This study presents the effectiveness of the endoscopic treatment of 73 consequent tracheal stenosis, using the same consistent approach in every individual patient.

\section{Methods}

\section{Design of the study}

We performed a retrospective analysis considering all of the new cases treated in our center during the four-year period between 1998 and 2001. Data were collected from the patients' files and by a brief telephone-interview. The patients or their relatives were contacted by the same physician in June 2004 to investigate whether they were symptomatic or not and to complete their medical history since the last hospital discharge. Most of the patients were subsequently evaluated endoscopically.

We classified tracheal stenoses into "true" stenoses, granulomas and "pseudoglottic" stenoses. "True" stenoses are further divided into "web-like" and "complex" stenoses.

Web-like stenoses are defined as mostly circumferential strictures of the trachea involving the mucosa of a short segment (maximum $1 \mathrm{~cm}$ in length), in some cases with inflammation, but without any damage to the cartilages [25].

Complex stenoses are sleeve strictures of the trachea more than $1 \mathrm{~cm}$ long or stenoses with various degrees of cartilage involvement, possibly associated with malacia and inflammation.

Finally, pseudoglottic stenosis are defined as " $A$ " shaped stenosis due to fracture of a cartilaginous ring secondary to tracheotomy.

\section{Subjects}

During the study period, 113 patients with a clinical history, functional, radiological or endoscopic evidence of tracheal stenosis related to intubation and/or tracheotomy were considered. All of the patients were symptomatic, presenting with dyspnea on effort in most cases. Only few patients complained of dyspnea at rest and no one presented with respiratory failure. In most patients the diagnosis of tracheal stenosis was made between 4 and 8 weeks after extubation or removal of the tracheo-cannula; in one case it was documented about 20 years after extubation. Symptoms occurred after the woman had significantly gained weight and developed ischemic cardiac disease.

After initial analysis of clinical data, eleven patients were excluded because they underwent one or more unsuccessful endoscopic procedures at different centres prior to being referred to us. As it was not possible to clearly define the timing and methods used, we decided not to include these subjects in the study.

On the basis of their first endoscopic evaluation 21 other patients were excluded from the study because their tracheal stenosis did not meet the criteria for "true stenosis" as defined in our design of the study. This group included 17 cases of granulomas, one fibrotic bridge between the vocal cords and three pseudoglottic stenoses.

The patients included in the study were then classified into two categories: web-like and complex stenosis (see the "Design of the study" for details).

Among the so selected 81 "true stenoses", eight cases of complex stenoses were excluded as they were just addressed to us by surgeons in order to overcome an urgent condition and to obtain a precise description of the stenosis itself for better timing of the intervention. After a single "bridge" laser reduction of the tracheal stenosis aimed at eliminating acute respiratory symptoms, they were sent back to the surgeon. This group consisted of healthy young patients with short segmental stenoses involving the cartilaginous rings.

Eventually 73 patients ( 72 Caucasian, 1 NorthAfrican) (47 males) aged 50 \pm 21 years (median: 52 years, range: 12-84 years) entered the study (tab. 1). Nine patients were from the geographical area covered by our hospital (12\%), while most patients $(88 \%)$ were referred from different regions of Italy. The indications for mechanical ventilation in these patients were various (tab. 2). Twenty-eight patients $(38 \%)$ had no underlying medical problems, whereas 47 patients (58\%) presented different co-morbidities (tab. 3).

Thirty-eight patients $(52 \%)$ had developed a tracheal stenosis after intubation (days of intubation: $11 \pm 10)$; the remaining 35 patients $(48 \%)$ underwent subsequent percutanous or surgical tracheotomy. Among these post-tracheotomy stenoses only two were located at a low level of the trachea and were due either to the tip of the tracheo-cannula or to its cuff. Most of them (33 out of 35) were located around the stoma site.

\section{Technical aspects}

All therapeutic bronchoscopies were performed using a rigid bronchoscope (Efer, DumonHarrel type; FR) under monitored general anesthesia in the bronchoscopy suite $[28,29]$, with stan- 
Table 1. - Patients' characteristics

\begin{tabular}{ccccc}
\hline & Sex & Age & \multicolumn{2}{c}{ Cause of stenosis } \\
\hline Males & Females & $y r s$ & Intubation & $\begin{array}{c}\text { Intubation } \\
\text { and tracheotomy }\end{array}$ \\
\hline 47 & 26 & $\begin{array}{c}50 \pm 21 \\
(12-84)\end{array}$ & 38 & 35 \\
\hline
\end{tabular}

Table 2. - Indications for assisted ventilation

\begin{tabular}{lcc}
\hline & n. pts & \% of total \\
\hline Trauma & 19 & 26 \\
$\begin{array}{l}\text { General surgery } \\
\text { (other than cardiac) }\end{array}$ & 12 & 16 \\
Cardiac surgery & 19 & 27 \\
\hline Medical causes & 23 & 31 \\
$\quad$ respiratory failure & 8 & 11 \\
$\quad$ acute heart failure & 9 & 12 \\
$\quad$ neurological failure & 2 & 3 \\
miscellaneous & 4 & 5 \\
\hline
\end{tabular}

Table 3. - Coexisting Underlying Diseases

\begin{tabular}{lcc}
\hline & pts & \% of total \\
\hline Systemic Hypertension & 26 & $32 \%$ \\
Heart Disease & 37 & $46 \%$ \\
Lung Disease & 10 & $12 \%$ \\
Obesity & 11 & $14 \%$ \\
Diabetes Mellitus & 8 & $10 \%$ \\
No underlying diseases & 28 & $38 \%$ \\
\hline
\end{tabular}

dard techniques. In some cases, a flexible fiberoptic bronchoscopy was performed (Pentax, 15-18 $\mathrm{X})$ prior to the therapeutic intervention, in order to better evaluate the airways and plan a prospective intervention by rigid bronchoscopy.

Our endoscopic treatment was based on the use of three main techniques: laser photo-resection, gentle dilation and possible removable stents.

Laser photo-resection was performed using a diode laser (Dornier Medilas D $60 \mathrm{~W}$ ) operating at a wavelength of $940 \mathrm{~nm}$ with continuous contact mode (20-25 W). The Light Protection System (LPS) suspends the laser emission to avoid carbonization and to control excessive heating of adjacent tissues. According to the technique described by Shapshay [31] we performed multiple radial incisions (3 to 4 ) through the entire vertical length of the stenotic tract using a standard fiber with a 60-micron diameter inserted in a fiber bronchoscope. The amount of total light energy delivered in each case varied from 200 to 700 joules depending on the thickness and length of the steno- sis. Gentle dilation with bronchoscopes of progressive caliber (Dumon-Harrel type; FR) was performed following laser resection.

Removable endotracheal stents were inserted if the stenoses relapsed after LAMD or during the initial procedure in case of unstable stenoses. An unstable stenosis is defined as an evolving stenosis, not yet well delimitated or maturated into a fibrous stricture, presenting malacia and/or inflammation. In most cases soft cylindrical silicon stents were placed and Montgomery T-tubes were used when tracheotomy was present (Novatech, Fr or Hood, USA). The largest and shortest possible cylindrical stent was selected with a caliber from 2 to $3 \mathrm{~mm}$ greater than the major rigid bronchoscope inserted to dilate the stenosis. The stent was $3 \mathrm{~mm}$ longer than the stenosis itself, at both proximal and distal ends. The standard period of stent placement was 12 months.

\section{Decision-making algorithm}

After the stenosis was diagnosed, the treatment was defined on the basis of clinical and anatomical criteria.

We normally consider the caliber of the stenosis, which is responsible for the severity of symptoms (critical or non-critical stenosis), the length of the stenosis, its location (distance from carina and vocal cords), the degree of cartilaginous involvement and the presence and severity of inflammation. Also clinical aspects such as age and co-morbidities influence the therapeutic choice.

All of these considerations guide our therapeutic algorithm as shown in figure 1 .

\section{Re-evaluations}

Stenosis recurrence after the endoscopic treatment is possible but not mandatory. If it occurs in an asymptomatic patient a new endoscopic dilation is neither necessary, nor useful.

Thus we consider a routine scheduling surveillance bronchoscopy in asymptomatic patients unwarranted.

All of the patients were re-evaluated by clinical examination and bronchoscopy in the case of symptoms recurrence or one year after treatment or stent removal. At this time the stenosis should have come to a stable point and the results can be considered definitive. For the same reason, only at this moment a complementary treatment may be taken into consideration if the endoscopic results are not fully satisfactory. 


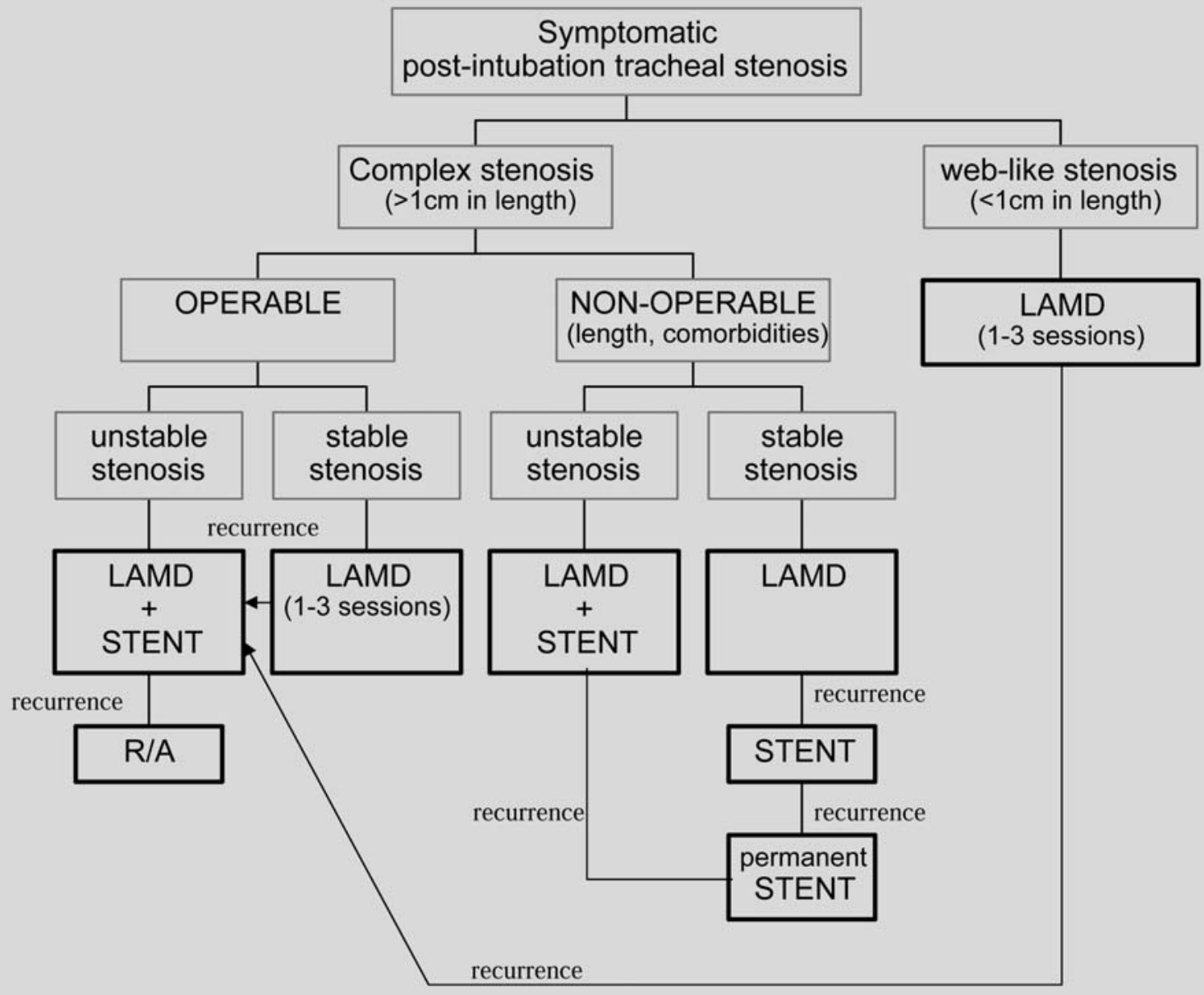

Fig. 1. - Therapeutic algorithm. Critical stenosis: diameter less than $5 \mathrm{~mm}$. R/A: Resection and Anastomosis. LAMD: Laser Assisted Mechanical Dilation; Stable Stenosis: well delimitated stenosis maturated into a fibrous stricture.

Tracheal stenoses were considered cured if patients were asymptomatic, even with exercise challenge, and if the endoscopically determined diameter of the trachea remained satisfactory (about 1 $\mathrm{cm}$ ) one year after the treatment was completed.

\section{Results}

\section{Patient recruitment and follow up}

We were able to contact each patient personally or indirectly through a close relative if the patients were not able to collaborate. The follow-up period after the last treatment of stenosis was of at least 28 months for patients who enrolled during the last few months of the year 2001, with a maximum of 78 months for patients who were referred to our centre in 1998.

Seventy-three patients (47 males) aged $50 \pm 21$ years entered the study: 60 with complex stenosis (82\%) and 13 with web-like stenosis (17.8\%).

The severity of the stenosis depended on the diameter of the residual lumen which varied from 3 to $8 \mathrm{~mm}$ (fig. 2). Two stenoses with $1 \mathrm{~mm}$ diameter were supra-stomic stenoses and the patients could breathe through a tracheal-cannula.

\section{Web-like stenosis}

All of the patients in this group had an excellent outcome. Nine out of thirteen patients $(69 \%)$ were cured with a single LAMD procedure; three patients required a second LAMD (23\%) after a mean of nine months. In one case, at the time of relapse, a Dumon silicon stent was left in place for one year to guarantee airway patency; it was a preventive measure since that particular patient lived on a little island far from the hospital.

The endoscopic treatment had a $100 \%$ success rate for web-like stenoses: $93 \%$ by LAMD alone and only in one case (7\%) with complementary stenting.

\section{Complex stenosis}

Thirteen patients with complex, stable stenosis were successfully treated in one single LAMD session $(13 / 60 ; 22 \%)$.

Forty-seven patients $(47 / 60 ; 78 \%)$ required stent placement, 15 had a T tube placed, 26 a cylindrical silicon stent and 6 were treated with both devices at different occasions. 


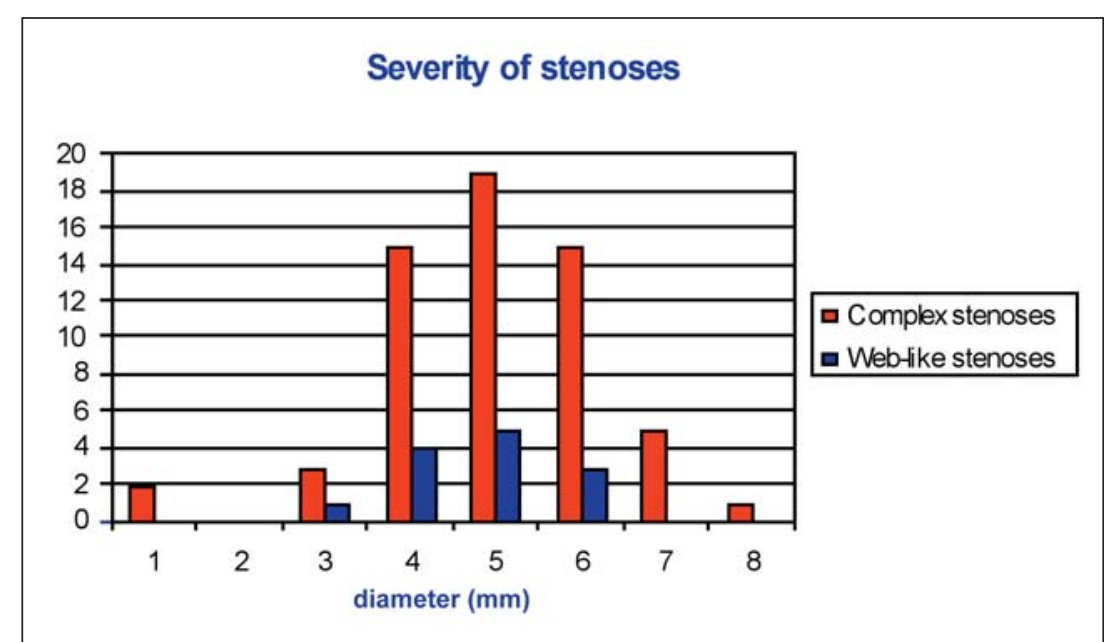

Fig. 2. - The severity of the stenosis depended on the diameter of the residual lumen which varied from 3 to $8 \mathrm{~mm}$. Two stenoses with $1 \mathrm{~mm}$ diameter were supra-stomic stenoses and the patients could breathe through a tracheal cannula.

22 patients had stable, good results after stent removal, from both an endoscopic and clinical point of view $(22 / 60 ; 37 \%)$. The mean duration of stenting was $11.6 \pm 4.6$ months (fig. 3). In all these patients but three the stent was placed at the first endoscopic treatment since the stenoses appeared unstable and they were judged cured after stent removal a mean of $12.5 \pm 4.6$ months later. In three cases an initial LAMD was performed with radical intent for the stenoses; though longer than $1 \mathrm{~cm}$, there was no important inflammation or cartilaginous involvement. A mean of 1.7 months later (3, 1 and 1 month respectively) these stenoses recurred and a stent was placed at this second session and removed respectively 10, 13 and 12 months later with a good definitive result in the two former patients. The latter required a second LAMD for partial recurrence 22 months after removal of the Dumon stent. Eventually a satisfacto-

\section{Duration of stenting}

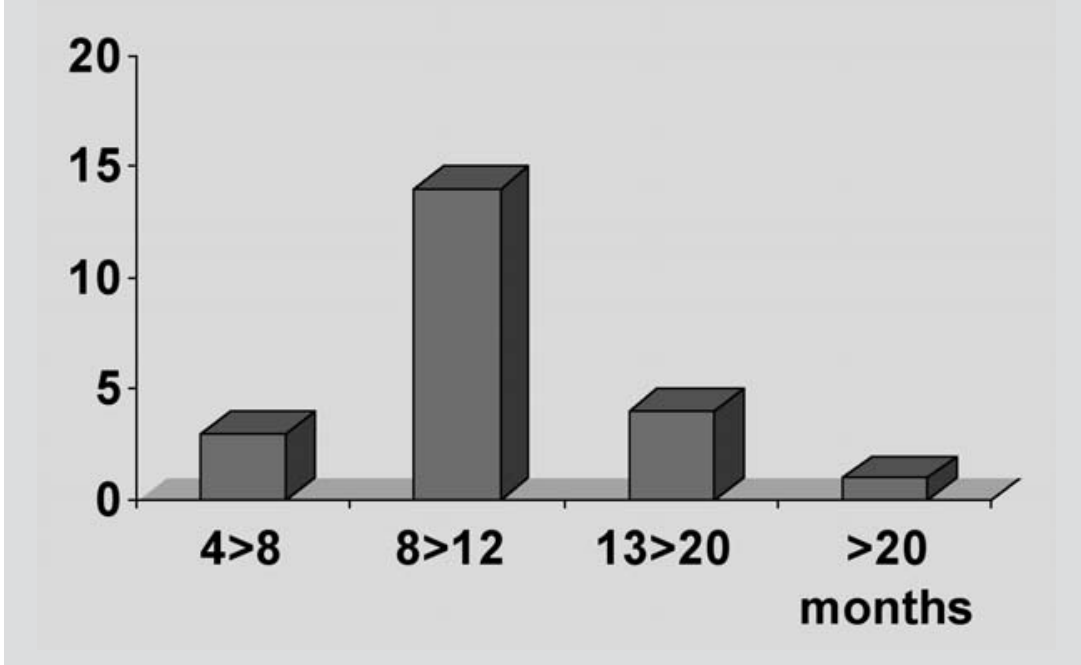

Fig. 3. - Duration of successful stenting (i.e. mean value made on the population whose stent has been removed) in complex stenoses varied from 3 to 25 months, the mean duration was $11.6 \pm 4.6$ months. Most patients (12/22) had their stent placed for 12 months. ry functional and endoscopic result was also achieved.

In thirteen cases $(13 / 60$; $18 \%$ ) the standard stenting period of one year was not sufficient to resolve the stenosis. Since these patients were considered as non-surgical, they still have eight T-tubes, four cylindrical stents in place and one tracheostomy tube; these devices are well tolerated and patients have a good quality of life. For these reasons we considered these cases as partial successes.

Finally, twelve patients $(12 / 60 ; 20 \%)$ have been referred to the surgeon for tracheal resection and anastomosis after failure of multiple endoscopic treatments $(3 \pm 1$ treatments $)$ including an attempt of stenting (13.3 \pm 4.9 months) normally performed at the first treatment except for one patient who relapsed one month after an initial LAMD. In almost half of the cases (5/12) tracheal resection was indicated at stent removal since the stenosis immediately recurred (malacia); in seven patients the stenoses recurred a mean of 3.6 \pm 2.3 months after stent removal and tracheal resection was then performed.

Considering the whole series, 48 patients (48/73: 66\%) obtained a stable, good result with the endoscopic procedure (fig. 4).

\section{Complications and Mortality}

No severe or permanent complications of LAMD occurred.

Among the 87 stents placed in 48 patients, few complications defined as intricacy requiring an endoscopic intervention were observed; obstruction of the stents by thick secretions occurred in $6 \%$ of the cases (5/87 stents) causing an attack of severe, acute dyspnea and moderate oxygen desaturations due to hindrance to secretion drainage, but never endangering patient survival. In all these cases the stent had to be replaced. Migration of the stent was documented in $10 \%$ of cases (9/87 stents). It occurred after a quite variable period of time after insertion ranging from less than one week (33\% of cases) to a maximum of three months.

\section{Discussion}

It is a difficult task to evaluate the efficacy of the endoscopic treatment for tracheal 


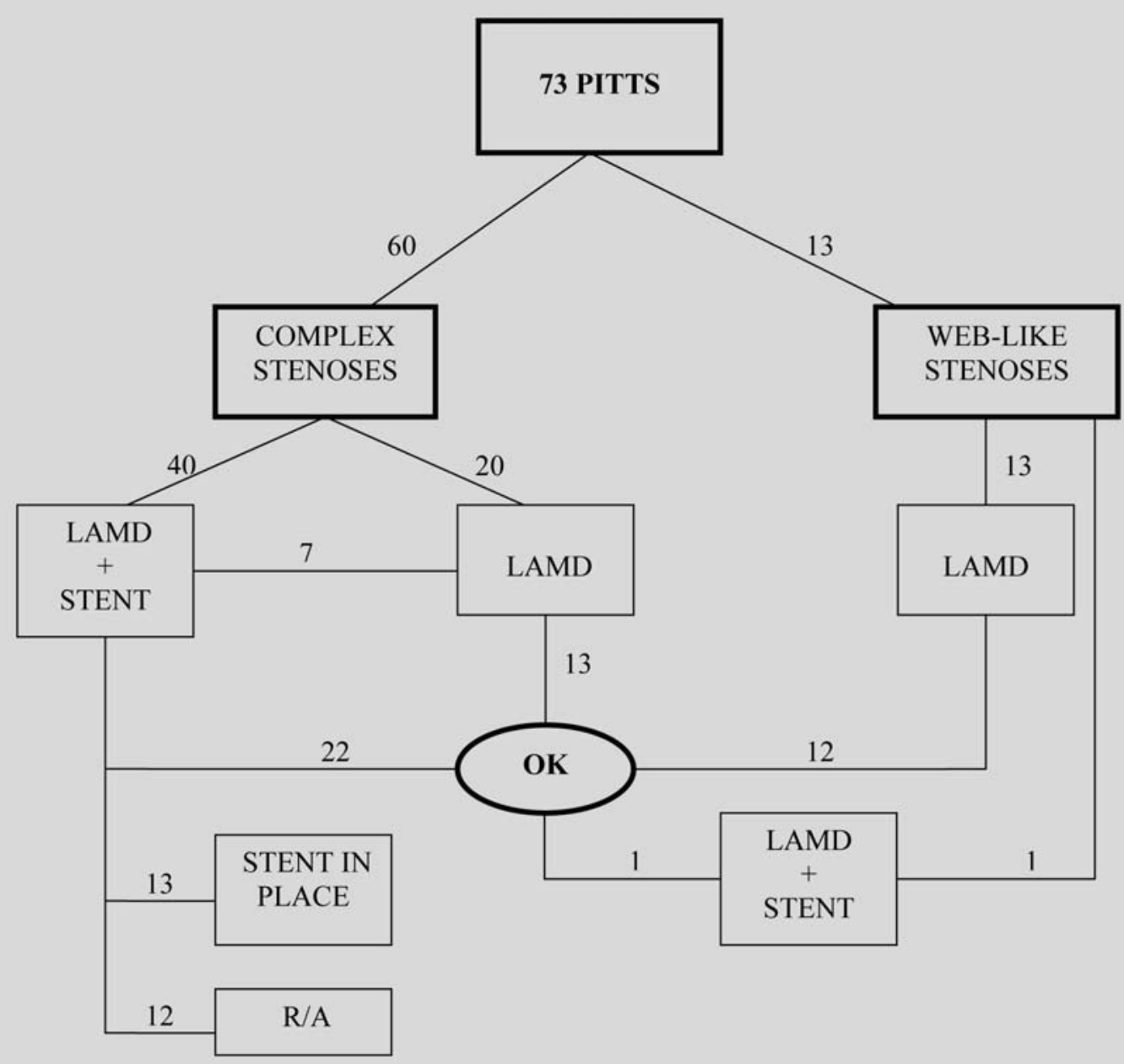

Fig. 4. - Results. PITTS: post-intubation/tracheotomy tracheal stenoses. R/A: resection/anastomosis. LAMD: Laser Assisted Mechanical Dilation.

stenosis related to intubation. Because tracheal stenosis is a fairly rare disease treated in different medical centres with a variety of therapeutic approaches, research on the outcome is difficult.

Thus, all cases of tracheal stenosis should be evaluated and treated in a restricted number of specialized centres, enabling them to reach meaningful experience.

Even for our centre serving as a referral hospital, it took a long period of time to collect a sufficient number of patients treated with the same standardised technique and to evaluate the results over an extensive follow-up period to include potential late recurrences. For this reason the most recent patients were not included in this study.

The endoscopic approach to tracheal stenosis should be compared to the surgical one, which, in the last few years, has definitely improved, achieving remarkable results with few complications.

In theory, the surgical point of view is correct: in best series resection with subsequent anastomosis is successful in over $90 \%$ of cases $[5,7,8]$, while the endoscopic treatment has a success rate ranges from 32 to $66 \%$, depending on the study [ 9 , $10]$. Therefore, all the operable cases should undergo open surgery; only patients with any con- traindication to surgery, or those who relapse after tracheal resection and reconstruction should be treated with therapeutic bronchoscopy. According to surgeons, an ancillary endoscopic treatment can only be considered prior to open surgery when temporary contraindications exist, in particular if the patient presents with a very tight, unstable stenosis with significant inflammation.

In practice, the majority of surgeons tend to save the endoscopic treatment for cases relapsing after surgery. Contrary to this approach we treated almost every post-intubation stenosis endoscopically trying to achieve a definitive result; only the cases relapsing after two or three LAMD sessions and at least one attempt of stenting were sent to the surgeon. Some surgeons affirm that the prior use of a stent and/or of laser procedures could increase the extent of injury and the length of stenosis [5]. In none of the patients in these series who required open surgery after recurrence of the stenosis it has been necessary to extend the length of the resection over the original length of the stenosis.

For those patients judged inoperable because of the length of the stenosis or the presence of severe risk factors (e.g. advanced age and co-mor- 
bidity), endoscopic treatment is the only alternative offering improved quality of life.

Even the endoscopic treatment of critical stenoses (diameter less than $5 \mathrm{~mm}$ ), regardless of the type of stenosis, is almost universally accepted to overcome the acute condition without using more invasive procedures such as tracheotomy $[4,8,19,30]$.

Endoscopic therapy is also effective in patients with simple lesions (web-like stenosis) and the choice of this conservative approach is justified by the high success rate $[10,13,18,20,31](100 \%$ in this study, $92 \%$ of whom by LAMD alone). We have noticed that, as far as web-like stenoses are concerned, our team achieves considerably better results than other studies in the field [25]. According to our definition web-like stenoses are short (maximum $1 \mathrm{~cm}$ ), circumferential strictures of the trachea involving only the mucosa. As shown by our data, thanks to the latter characteristic, laser ablation performed by experienced hands can be curative in this kind of stenosis.

Among patients with complex stenoses susceptible for surgical anastomosis, the therapeutic approach is more debatable.

We treat all complex symptomatic stenoses endoscopically pursuing the possibility of a radical treatment. We have noticed that the most important factor in predicting the outcome of the endoscopic dilation is the grade of cartilaginous involvement. A pre-treatment work-up including, besides clinical and endoscopic evaluation, also advanced imaging techniques (multi-slice CT with spatial reconstruction) may be quite useful to define the extramural extension, the length of the stenosis and most of all, the possible cartilage involvement.

In our series LAMD alone has been curative in $22 \%$ of complex stenoses. We treated by LAMD alone only very selected stable stenoses, without inflammation, signs of severe cartilaginous involvement or malacic tracts. This fine selection justifies the high success rate of LAMD alone in complex, stable stenoses.

To achieve definitive results we also used endotracheal stents, usually placed as the first approach in unstable stenoses or at the first recurrence after LAMD when the stenosis appeared mature at our initial evaluation. In fact, we resorted to a stent only in 4 out of $18(22 \%)$ stenoses treated with LAMD alone, since judged mature.

If the endoscopic treatment leads to a stable result, surgery may no longer be necessary. Moreover, in some elderly patients or subjects with major co-morbidities, the endoscopic treatment may be sufficient and allow the patient to avoid open surgery. It must be emphasised that many patients affected by tracheal stenosis are elderly patients presenting with chronic underlying diseases often being the initial cause for intubation and assisted ventilation. In particular, $20 \%$ of the patient in our study developed tracheal stenosis after intubation for cardiac surgery. Twelve percent suffered from a variety of lung diseases, often complicated by chronic respiratory failure. Some other patients were quadriplegic and in such circumstances surgery represents an unnecessary risk. In fact for these kind of patients a sub-normal caliber of the trachea (1 cm or little more) may be sufficient as they are bed-ridden and do not require significant reserve ventilation for exercise. In case of failure, the endoscopic treatment in this pre-surgical phase allows fine anatomical descriptions, evaluates the degree of the stenosis and for better surgical timing, plays a pivotal role that is appreciated by the most experienced surgeons [7, 30].

The success of surgery is directly related to the selection of the right procedure as well as proper timing and appropriate patient preparation.

Although we have a satisfactory success rate with the endoscopic treatment, we do not hesitate in referring some selected patients to the surgeon, d'emblée or after an exclusively preoperative endoscopic treatment for the most critical stenoses. These are typically young otherwise healthy patients, affected by complex stenoses 1 to 4 centimeters in length, with the remaining part of the trachea undamaged.

Complications of surgical resection and anastomosis for post-intubation tracheal stenosis have decreased progressively, having, according to the most recent literature, a $5-15 \%$ failure rate $[5-8$, $26,27,32-36]$, but still including some postoperative mortality. By contrast there is no mortality in the most qualified endoscopic series. Moreover, some complications of open surgery are permanent, such as vocal cord paralysis, which is observed in 5\% of patients [4] whereas no permanent complications secondary to the endoscopic treatment were observed.

In conclusion, therapeutic bronchoscopy has greatly modified the approach to the management of post-intubation tracheal stenosis. The treatment must be performed in an expert setting, it should be based on an initial endoscopic evaluation, aimed at determining the type and the extension of the stenosis as well as the degree of scar maturation. A CT scan evaluation is mandatory for a precise description of the extra-mural involvement and, as a consequence, to plan the most effective treatment. Selected cases should then be referred to the surgeon, directly or after urgent treatment, while the majority of tracheal stenoses (particularly web-like) can be successfully treated using therapeutic endoscopy. In case of unsuccessful cases, patients can always be referred for surgical procedure at the later time.

Acknowledgements: The authors are grateful to Dr. Gregory Cieslewicz for his help in preparing this manuscript.

\section{References}

1. Cooper JD, Grillo HC. Experimental production and prevention of injury due to cuffed tracheal tubes. Surg Gynecol Obstet 1969; 129: 1235-41.

2. Knowlson GTG, Bassett HFM. The pressure exerted on the trachea by tracheal inflatable cuffs. Br J Anaesth 1970; 42: 834-7.

3. Stauffer JL, Olson DE, Petty TL. Complications and consequences of tracheal intubation and tracheotomy. 
A prospective study of 150 critically ill adult patients. Am J Med 1981; 70: 65-76.

4. Wain JC. Post-intubation tracheal stenosis. Chest Surg Clin N Am 2003; 13: 231-246.

5. Rea F, Callegaro D, Sartori F. Benign tracheal and laryngotracheal stenosis: surgical treatment and results. Eur J Cardiothorac Surg 2002; 22: 352-6.

6. Bisson A, Bonette P, Ben El Kadi N. Tracheal sleeve resection for iatrogenic stenosis. J Thorac Surg 1995; 60: 250-9.

7. Couraud L, Jougon JB, Velly JF. Surgical treatment of nontumoral stenoses of the upper airway. Ann Thorac Surg 1995; 60: 250-9.

8. Grillo HC, Donahue DM, Mathisen DJ. Postintubation tracheal stenosis. Treatment and results. J Thorac Cardiovasc Surg 1995; 109: 486-93.

9. Strausz J. Management of Postintubation tracheal stenosis with stent implantation J Bronchol 1997; 4: 294-296.

10. Mehta AC, Lee FYW, Cordasco EM. Concentric tracheal and subglottic stenosis. Chest 1993; 104: 673-77.

11. Cavaliere S. Le endoprotesi tracheobronchiali. Rass Patol App Resp 1990; 5: 225-226.

12. Vergnon JM, Costes F, Polio JC. Efficacy and tolerance of a new silicon stent for the treatment of benign tracheal stenosis- preliminary results. Chest 2000; 118: 422-426.

13. Colt HG, Dumon JF. Lasers and endoprosthesis in bronchopneumology. Rev Pneumol Clin 1991; 47: 65-73.

14. Dumon JF, Cavaliere S, Diaz-Jimenez JP, et al. Sevenyear experience with the Dumon prosthesis. J Bronchol 1996; 3: 6-10.

15. Dumon JF, Meric B, Cavaliere S, Vilcoq P. Indwelling tracheobronchial prosthesis. Chest 1988; $94: 68 \mathrm{~S}$

16. Colt HG. The art and science of airway stenting. $J$ Bronchol 1995; 2: 263-266.

17. Noppen M, Meysman M, Claes I. Screw-thread vs Dumon endoprosthesis in the management of tracheal stenosis. Chest 1999; 115: 532-535.

18. Martinez- Ballarin JI, Diaz-Jimenez JP, Castro MJ, Moya JA. Silicone stents in the management of benign tracheobronchial stenoses. Chest 1996; 109: 626-29.

19. Puma F, Ragusa M, Avenia N. The role of silicon stents in the treatment of cicatricial tracheal stenosis. J Thorac Cardiovasc Surg 2000; 120: 1064-9.

20. Simpson GT, Strong MS, Healy GB, Shapsay SM. Predictive factors for success or failure in the endoscopic management of laryngeal and tracheal stenosis. Ann Otol Rhinol Laryngol 1982; 91: 384-88.

21. Strong MS, Healy GB, Shapsay SM. Endoscopic management of laryngeal stenosis. Otolaryngol Clin North Am 1979; 12: 797-805.
22. Friedman EN, Healy GB, McGill TJ. Carbon dioxide laser management of subglottic and tracheal stenosis. Otolaryngol Clin North Am 1983; 16: 871-77.

23. Ossoff RH, Tucker GF Jr, Duncavage JA. Efficacy of bronchoscopic carbon dioxide laser surgery for benign strictures of the trachea. Laryngoscope 1984; 94 : 445-50.

24. Spittle N, McCluskey. Tracheal stenosis after intubation. BMJ 2000; 321: 1000-2.

25. Brichet A, Verkindre C, Dupont J, Marquette CH. Multidisciplinary approach to management of postintubation tracheal stenoses. Eur Resp J 1999; 13: 888-893.

26. Ribet M, Bugnon P, Darras J. Chirurgie des sténoses inflammatoires et tumorales de la trachée. A propos de 38 cas. Rev Mal Respir 1990; 7: 349-353.

27. Bonnette P, Colchen A, Leroy M. Résection anastomose trachéale. pour sténose iatrogène Une experience de 340 cas. Rev Mal Respir 1998; 15: 627-632.

28. Natalini G, Cavaliere S, Vitacca M. Negative pressure ventilation vs spontaneous assisted ventilation during rigid bronchoscopy. Acta Anaesthesiol Scand 1998; 42: 1063-1069.

29. Vitacca M, Natalini G, Cavaliere S, et al. Breathing pattern and arterial blood gases during Nd-YAG laser photoresection of endobronchial lesions under general anesthesia. Chest 1997; 112: 1466-73.

30. Grillo HC. Urgent treatment of tracheal obstruction. In Grillo HC (Ed.) Surgery of trachea and bronchi. BC Decker Inc., 2004.

31. Shapshay SM, Beamis JF, Hybels RL. Endoscopic treatment of subglottic and tracheal stenosis by radial laser incision and dilatation. Ann Otol Rhinol Laryngol 1987; 96: 661-664.

32. Maddaus MA, Toth JLR, Gullane PJ and Pearson FG. Subglottic tracheal resection and synchronous laryngeal reconstruction. J Thorac Cardiovasc Surg 104; 5: 14431450.

33. Laccourreye O, Brasnu D, Laccourreye H. Tracheal resection with end-to-end anastomosis for isolated postintubation cervical tracheal stenosis: long-term results. Ann Otol Rhinol Laryngol 105: 1996.

34. Laccourreye O, Brasnu D, Laccourreye H. Cricotracheal anastomosis for assisted ventilation-induced stenosis. Otolaryngol Head Neck Surg 1997; 123: 1074-1077.

35. Har-El G, Chaudry R, Lucente FE. Resection of tracheal stenosis with end-to-end anastomosis. Ann Otol Rhinol Laryngol 102: 1993.

36. Har-El G, Lim JW, Wynn R Tracheal resection with end-to-end anastomosis for benign tracheal stenosis. Ann Otol Rhinol Laryngol 113: 2004.

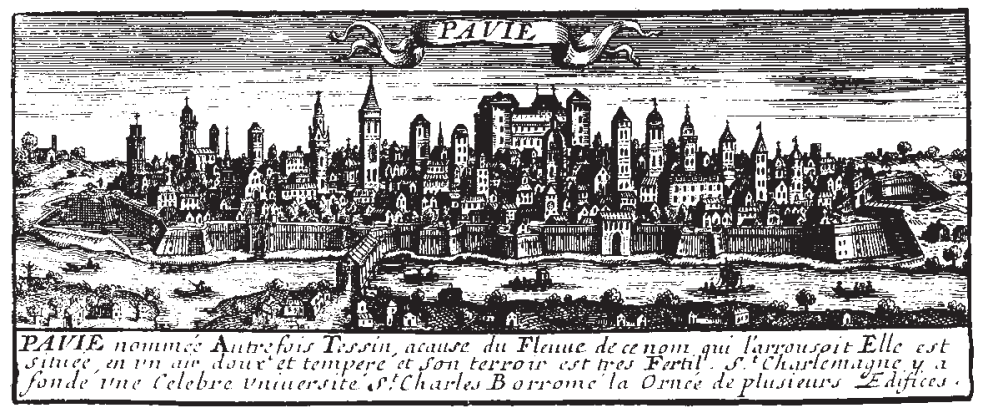

